\title{
Effect of Menopause on Pulmonary Functions: An Analysis!
}

\author{
${ }^{1}$ Amar K Karia, ${ }^{2}$ Kshama V Kedar, ${ }^{3}$ Radha P Munje
}

\begin{abstract}
Introduction: Sex hormones play an important role in women's health. There is a close relationship between female sex hormones and lung function in postmenopausal women. Deterioration of lung function is observed more after menopause. Estrogen deficiency after menopause accelerates the adverse effects of biological aging on lung mechanics in postmenopausal women. Our study uses a spirometer to analyze and evaluate these effects of menopausal aging.
\end{abstract}

Objective: To study the effects of menopause on pulmonary function tests in women of perimenopausal age group.

Materials and methods: This study was carried out in the Department of Obstetrics and Gynecology in Indira Gandhi Government Medical College \& Hospital (IGGMC) Nagpur, India. Totally 50 women each in premenopausal and menopausal age groups were included in our study. Venous blood was collected under aseptic precautions on 10 to 14 and 18 to 23 days corresponding to follicular and luteal phase of menstrual cycle in premenopausal and postmenopausal women. Serum estrogen and progesterone levels were estimated by microparticle enzyme immunoassay. The pulmonary function of all subjects was measured with digital microspirometer and data collected. The peak expiratory flow rate (PEFR), forced expiratory flow $(\mathrm{FEF})_{25-75}$, forced expiratory volume (FEV1), and forced vital capacity (FVC) were studied and correlated with symptoms. Data analysis was done using Student's unpaired t-test and chi-squared test.

Results: The mean percentages of predicted values of $\mathrm{FEF}_{25-75}$ and PEFR were lower in postmenopausal women compared with premenopausal women. Mean serum estrogen levels were significantly lower in postmenopausal women as compared with premenopausal women. Progesterone levels were lower in postmenopausal women and in proliferative phase of premenopausal women as compared with luteal phase of menstrual cycle.

Conclusion: As menopause sets in, decrease in hormonal levels leads to decreased lung capacity as evident by pulmonary function tests. Decreased pulmonary function test can be attributed to lower levels of sex hormones estrogen and progesterone in postmenopausal women.

Keywords: Estrogen, Menopause, Progesterone, Pulmonary function test, Spirometry.

\footnotetext{
${ }^{1}$ Junior Resident, ${ }^{2}$ Associate Professor, ${ }^{3}$ Professor

${ }^{1-3}$ Department of Obstetrics and Gynecology, Indira Gandhi Government Medical College \& Hospital, Nagpur, Maharashtra India
}

Corresponding Author: Amar K Karia, Junior Resident Department of Obstetrics and Gynecology, Indira Gandhi Government Medical College \& Hospital, Nagpur, Maharashtra India, Phone: +917720046160, e-mail: amarkaria98@gmail.com
How to cite this article: Karia AK, Kedar KV, Munje RP. Effect of Menopause on Pulmonary Functions: An Analysis! J South Asian Feder Menopause Soc 2017;5(2):99-101.

Source of support: Nil

Conflict of interest: None

Date of received: 02 July 2017

Date of acceptance: 05 September 2017

Date of publication: December 2017

\section{INTRODUCTION}

Pulmonary function changes are associated primarily with aging, but ovarian hormones also have a certain impact on them. All sex steroid hormone receptors have been shown to be expressed in lung tissue. ${ }^{1}$ A new hormonal pattern is established at menopause, which is characterized by a rise in the circulating levels of follicle stimulating hormone and luteinizing hormone and comparatively low levels of estrogen and progesterone. ${ }^{2}$ In postmenopausal women, along with other organ system dysfunctions, lung functions are also adversely affected. ${ }^{3}$ The respiratory system undergoes various structural, physiological, and immune changes with age. There is an increase in airspace size with aging, resulting from the loss of supporting tissue. Loss of lung function occurs quickly in postmenopausal women, and respiratory muscle strength decreases with age. ${ }^{4,5}$ Several studies have reported about hyperventilation and bronchial relaxation being associated with high progesterone levels during luteal phase of menstrual cycle. ${ }^{6,7}$ Thus, decreased pulmonary function can be attributed to low levels of sex hormones in postmenopausal women.

Therefore, our study was undertaken with the objective of observing serum levels of sex hormones estrogen and progesterone and to identify their effects on pulmonary function in pre- and postmenopausal women.

\section{MATERIALS AND METHODS}

A cross-sectional study was carried out in the Department of Obstetrics and Gynecology in IGGMC Nagpur, India after taking approval from the institutional ethical committee. Totally 50 women in premenopause (group I) and 50 women with menopause (group II) were included in our study. Women in group I were staff working in IGGMC Nagpur and were assessed twice, once on 10 to 14 days (group $\mathrm{I}_{1}$ ) and then on 18 to 22 days (group $\mathrm{I}_{2}$ ) of 
menstrual cycle. Women in group II were selected from patients coming to the gynecology outpatient department. After taking past and personal and family history, a complete physical examination was done. After taking written informed consent, pulmonary function of all subjects was measured with digital microspirometer and data collected. The PEFR, FEF $25-75$, FEV1, and FVC were studied and correlated with symptoms. About $5 \mathrm{~mL}$ of venous blood was collected under aseptic precautions in both groups and serum estrogen and progesterone levels were estimated using microparticle enzyme immunoassay. Data collected were analyzed using unpaired t-test and chi-squared test.

\section{Inclusion Criteria}

Women in premenopause and postmenopausal stages with varying years of menopause.

\section{Exclusion Criteria}

- Women with preexisting respiratory or cardiovascular disorder.

- Women with history of smoking, hypertension, diabetes mellitus, and hormone replacement therapy were excluded.

For assessing lung function, a spirometry was done using a computer-based digital spirometer.

Parameters studied were

- $\mathrm{FEV}_{1}$

- FVC

- $\mathrm{FEF}_{25-75}$

- PEFR

\section{RESULTS}

Mean percentage of predicted values of $\mathrm{FEF}_{25-75}$ and PEFR was lower in group II as compared with groups $I_{1}$ and $\mathrm{A}_{2}$ (Tables 1 and 2).

Table 1: Mean percentage of predicted values of $\mathrm{FEV}_{1}, \mathrm{FVC}$, PEFR, FEF $25-75 \pm$ standard deviation

\begin{tabular}{llll}
\hline & Group $I_{1}$ & Group $I_{2}$ & Group II \\
\hline FEV & $81.36 \pm 14.21$ & $83.24 \pm 12.15$ & $80.08 \pm 13.79$ \\
FVC & $80.32 \pm 13.36$ & $81.41 \pm 13.23$ & $78.08 \pm 11.89$ \\
PEFR & $77.23 \pm 16.51$ & $76.65 \pm 15.68$ & $70.58 \pm 10.18$ \\
FEF $_{25-75}$ & $62.59 \pm 16.79$ & $63.58 \pm 16.27$ & $55.29 \pm 17.01$ \\
\hline
\end{tabular}

Table 3: Mean \pm standard deviation of serum estrogen and progesterone levels

\begin{tabular}{llll}
\hline & Group I & Group I $_{2}$ & Group II \\
\hline $\begin{array}{l}\text { Estrogen } \\
(\mathrm{pg} / \mathrm{mL})\end{array}$ & $177.16 \pm 27.66$ & $172.59 \pm 20.12$ & $26.32 \pm 11.24$ \\
$\begin{array}{l}\text { Progesterone } \\
(\mathrm{ng} / \mathrm{mL})\end{array}$ & $0.79 \pm 0.17$ & $12.46 \pm 3.79$ & $0.49 \pm 0.15$ \\
\hline
\end{tabular}

The $\mathrm{FEV}_{1}$ and FVC also were lower in postmenopausal women, but there was no significant difference (Tables 1 and 2).

Mean serum estrogen level was significantly lower in group II as compared with groups $\mathrm{I}_{1}$ and $\mathrm{I}_{2}$ (Tables 3 and 4).

Mean progesterone level was significantly lower in group II as compared with group $I_{2}$, but not with group $I_{1}$. Mean progesterone level was significantly lower in group $\mathrm{I}_{1}$ as compared with group $\mathrm{I}_{2}$ (Tables 3 and 4).

\section{DISCUSSION}

Most of the postmenopausal women in our country fail to avail the existing health care services and, thus, suffer from complications due to poor lung function. In postmenopausal women, relationship between low level of estrogen and progesterone and the changes in $\mathrm{FEF}_{25-75}$ and PEFR have been explored by several investigators of different countries. ${ }^{8-10}$ In this study, mean percentage of predicted values of $\mathrm{FEF}_{25-75}$ and PEFR were lower in postmenopausal women.

Various mechanisms have been proposed for these observed changes in lung function in postmenopausal women. After menopause, the ovaries become less functional, and there is a reduction in the amounts of estrogen and progesterone produced by the ovary. A few studies have suggested that progesterone induces hyperventilation through both the central medullary and peripheral chemoreceptors. ${ }^{11}$ Estrogen and progesterone have been associated with relaxation of airway smooth muscles mediated by relaxation of bronchial muscles and widening of bronchi. ${ }^{12}$ The bronchial epithelium and smooth muscle contain alpha ${ }_{2}$ adrenergic receptors, which cause bronchodilation and increase secretion. ${ }^{11}$

Progesterone has beneficial effects on the upper airway function and breathing is supported by pharyngeal dilator muscle activity. ${ }^{13}$ All these effects are contributed

Table 2: Comparison of lung function parameters between the three groups

\begin{tabular}{lllll}
\hline $\begin{array}{l}\text { Statistical analysis } \\
(p \text {-value })\end{array}$ & FEV & FVC & PEFR & $F E F_{25-75}$ \\
\hline A1 vs A2 & 0.4788 & 0.6828 & 0.8587 & 0.9016 \\
A1 vs B & 0.6486 & 0.3780 & 0.017 & 0.0332 \\
A2 vs B & 0.2270 & 0.1887 & 0.023 & 0.0144 \\
\hline
\end{tabular}

Table 4: Comparison of estrogen and progesterone levels between the three groups

\begin{tabular}{lcc}
\hline Statistical analysis ( $p$-value) & Estrogen & Progesterone \\
\hline A1 vs A2 & 0.3471 & $<0.0001$ \\
A1 vs B & $<0.0001$ & 0.367 \\
A2 vs B & $<0.0001$ & $<0.0001$ \\
\hline
\end{tabular}


by estrogen and progesterone to increase lung function. Estrogen increases the number of progesterone receptors; therefore, the combining effect of estrogen with progesterone increases lung function. ${ }^{14}$ After menopause, there is a significant loss of bone mineral density. ${ }^{15}$ The cause of the bone loss after menopause is primarily due to estrogen deficiency. ${ }^{16}$ As a result, bone mass density in the bones of thoracic cage is also reduced. ${ }^{3}$ Due to deformities of bones of the thoracic cage, there is decrease in intrathoracic space, which is related to decreased lung function. ${ }^{17}$ Various investigators suggested that estrogen and progesterone cause increase in muscle strength and induce skeletal myoblast growth. ${ }^{18}$ Decreased estrogen and progesterone levels decrease strength of respiratory muscle. However, the exact mechanisms involved for lower lung function in postmenopausal women of the present study cannot be elucidated from this type of study. According to the suggestions made by different investigators, ${ }^{8,9}$ lower percentages of predicted values of FVC and $\mathrm{FEV}_{1}, \mathrm{PEFR}$, and $\mathrm{FEF}_{25-75}$ in postmenopausal women in comparison with premenopausal women during follicular and luteal phases are most likely due to decreased levels of progesterone and estrogen as observed in this study. Reduced levels of estrogen and progesterone would cause decreased muscular strength, decreased relaxation of bronchial smooth muscle, and increased compression of thoracic spine and, as a result, there is reduced total lung capacity.

\section{CONCLUSION}

Sex hormones play an important role in women's lung health. A close relationship between the sex hormones and pulmonary function has been observed in postmenopausal women. It may be concluded that reduced lung function in postmenopausal women may be related to their low estrogen and progesterone levels.

\section{REFERENCES}

1. Carey MA, Card JW, Voltz JW, Germolec DR, Korach KS, Zeldin DC. The impact of sex and sex hormones on lung physiology and disease: lessons from animal studies. Am J Physiol Lung Cell Mol Physiol 2007 Aug;293(2):272-278.

2. Parham, C. Heart spring. Concho (AZ): Heartspring; 20007. [cited 2007 Jun 4]. Available from: http://www.Heart spring.net.
3. Ganong, WF. Review of medical physiology 22nd edn. New York: McGraw-Hill; 2005.

4. Sharma G, Goodwin J. Effect of aging on respiratory system physiology and immunology. Clin Interv Aging 2006 Sep;1(3): 253-260.

5. Massaro D, Massaro GD. Toward therapeutic pulmonary alveolar regeneration in humans. Proc Am Thorac Soc 2006 Nov;3(8):709-712.

6. Manson EJ, Marti AK. Postmenopausal hormone replacement therapy. N Engl J Med 2001 Jul;345(1):34-40.

7. Balzano G, Fuschillo S, Mellilo G, Bonini S. Asthma and sex hormones. Allergy 2001 Jan;56(1):13-20.

8. Pata O, Atiş S, Utku Öz A, Yazici G, Tok E, Pata C, Kiliç F, Çamdeviren H, Aban M. The effect of hormone replacement therapy type on pulmonary functions in postmenopausal women. Maturitas 2003 Nov;46(3):213-218.

9. Cevrioglu AS, Fidan F, Unlu M, Yilmazer M, Orman A, Fenkci IV, Serteser M. The effects of hormone therapy on pulmonary function tests in postmenopausal women. Maturitas 2004 Nov;49(3):221-227.

10. Köksal N, Güven A, Celik O, Kiran G, Kian H, Ekerbiçer HC. The effects of hormone replacement therapy and pulmonary functions in postmenopausal women. Tuberk Toraks 2004;52(3):237-242.

11. Pai RS, Prajna P, Urban JA, D'Souza UJA. Correlative study IOB blood pressure and lung function profiles during different phases of menstrual cycle among Indian population. Thai J Physiol Sci 2004 Aug;17(2):30-34.

12. Foster PH, Goldie RG, Paterson JW. Effects of steroid on beta-adrenoceptor-mediated relaxation of pig bronchus. $\mathrm{Br}$ J Pharmacol 1983 Feb;78(2):441-445.

13. Popovic RM, White DP. Upper airway muscle activity in normal woman: influence of hormonal status. J Appl Physiol (1985) 1998 Mar;84(3):1055-1062.

14. Leavitt WW, Blaha GC. An estrogen-stimulated, progesteronebinding system in the hamster uterus and vagina. Steroids 1972 Feb;19(2):263-274.

15. Armamento-Villareal R, Civitelli R. Estrogen action on bone mass of postmenopausal women is dependent on body mass and initial bone density. J Clin Endocrinol Metab 1995 Mar;80(3):776-782.

16. Lindsay R, Hart DM, Aitken JM, Mc Donald EB, Anderson JB, Clarke AC. Long-term prevention of postmenopausal osteoporosis by estrogen. Evidence for an increased bone mass after delayed onset of estrogen treatment. Lancet 1976 May;1(7968):1038-1041.

17. Ross M, Marti G, Ricordi L, Farnasari G, Fratino P, Bernardi L. Cardiac autonomic dysfunction in obese subjects. Clin Sci (Lond) 1989 Jun;76(6):567-572.

18. Kahlert S, Grohé C, Karas RH, Löbbert K, Neyses L, Vetter H. Effects of estrogen on skeletal myoblast growth. Biochem Biophys Res Commun 1997 Mar;232(2):373-378. 